\title{
NOTA A DOS INVESTIGACIONES SOBRE LA "EPÍSTOLA MORAL"
}

\author{
P O R \\ JOSE ROJAS GARCIDUEÑAS
}

Curiosos, inexplicables, parecen ciertos hechos o sucedidos en el campo $\checkmark$ de la investigación: pasan años y nadie se interesa por un tema que está allí, como tantos más, en las páginas de los tratados y hasta de los manuales escolares, sabido y olvidado por los especialistas, que no se interesan ya en él. Pasan años y en cierto momento, casi al mismo tiempo, dos investigadores, cada uno en su mesa de trabajo, separados por miles de kilómetros, apila libros, toma notas, reflexiona, se inquieta, busca, estudia, repasa, va y viene en las idas y vueltas mentales típicas de toda investigación, finalmente escribe, redacta su estudio, lo hace público en la cátedra, en la tribuna académica, en las páginas impresas. No ha resuelto el problema tal vez, pero ha adelantado un trecho más allá del banderín que dejó el predecesor, muchos años antes. $Y$ al mismo tiempo, o casi al mismo tiempo, en otro país, en otro continente, otro especialista hace algo muy semejante y con igual resultado: avanza un paso o dos en el estudio del mismo tema. Y en este paralelismo simultáneo cada uno ignora lo que hace y lo que consiguió el otro.

Para quienes, por motivos profesionales, conocemos el terreno en que eso sucede, un caso así desconcierta, como tal vez no desconcertaría al profano en estos achaques. Porque nosotros sabemos que en el inmensurable campo de las investigaciones posibles, las áreas "pobladas" y "transitadas" (digámoslo en símil de geografía social), son muy escasas: los 
estudiosos e investigadores de la poesía en lengua castellana, ¿cuántos son?, y de ellos ¿cuántos los que conocen la bibliografía, las fuentes y se interesan por la historia de la poesía castellana del periodo barroco?, y de éstos ¿cuántos se interesarían por el problema del posible autor de un poema determinado? En suma, ¿cuántas personas podrían conocer y manejar las fuentes bibliográficas, buscar en los archivos, leer documentos de hace tres siglos, etc., para alcanzar a saber apenas muy poco más acerca de quién fue el autor y quién el sujeto o destinatario de la "Epístola Moral"?

Pues bien, este doblemente curioso caso de paralelismo en la investigación, con mutuo desconocimiento del trabajo realizado, ha ocurrido una vez más: en México don Manuel Toussaint y en España don Dámaso Alonso, se interesaron, estudiaron, investigaron y avanzaron un poco, cada uno aparte e ignorando lo que el otro hacía, en esa antes mencionada cuestión.

En varios aspectos esta situación es inconveniente y lamentable, porque dispersa los esfuerzos, los gasta inútilmente $\mathrm{y}$, sobre todo, porque amenguan los resultados, pues no parece insensato suponer que si cuando un investigador logra, tras de cierto tiempo y trabajo, avanzar un poco y otro investigador realiza labor análoga y paralela, se está duplicando un esfuerzo o esfuerzos que, coordinados o sucesivos, con mutuo conocimiento, sería posible (aunque no seguro, pues estas sumas no son matemáticas y todo lo relativo a investigaciones es en gran manera contingencial o aleatorio), que la distancia adelantada fuese, en conjunto, mayor que la obtenida por los dos esfuerzos paralelos e independientes.

Son esas consideraciones las que me han movido a redactar las notas siguientes, solamente para coordinar esas investigaciones aludidas.

El 8 de diciembre de 1954, don Manuel Toussaint leyó su discurso de recepción en la Academia Mexicana de la Lengua Correspondiente de la Española. En ese discurso dio noticia de ciertos datos relativos al Capitán Andrés Fernández de Andrada, presunto autor del poema que ya es tradicional denominar Epistola Moral, aquél cuyos primeros tercetos dicen:

Fabio, las esperanzas cortesanas prisiones son do el ambicioso muere 
y donde al más activo ${ }^{1}$ nacen canas, el que no las limare o las rompiere ni el nombre de varón ha merecido ni subir al honor que pretendiere.

La segunda parte del discurso la dedicó su autor a un breve análisis de la composición del poema y a la interpretación de algunas de sus metáforas. En este comentario me voy a referir solamente a la parte primera, o sea a los datos sobre Fernández de Andrada encontrados por Toussaint y a ciertas hipótesis que él plantea, en relación con determinadas circunstacias del poema y de su autor.

El señor Toussaint no dio inmediatamente a la estampa su discurso, a pesar de que el artículo 27 de los Estatutos de la Academia establece que el discurso de ingreso y el del académico que lo conteste deben imprimirse y entregar a la Academia ejemplares de ellos, para cumplir con otros preceptos de la Asociación de Academias de la Lengua Española. Don Manuel no lo hizo así porque, si no recuerdo mal, él deseaba hacer algunos retoques y añadir algunas notas a su texto; pero poco después de la fecha mencionada recibió la invitación para asistir al XVIII Congreso de Historia del Arte, en Venecia, y dedicó su tiempo, además de cumplir con sus labores habituales, a diversas tareas urgentes en relación con las representaciones que llevaría a dicha reunión y a preparar el viaje consiguiente. Salió de México el 19 de agosto de 1955, enfermó durante el regreso y murió en Nueva York el 22 de noviembre de aquel año. Eso explica que su discurso aparezca como inédito en la ficha No 281 de su Bibliografía, publicada en el Suplemento No 1 del No 25 de estos Anales (fechado en 1957, pero que fue redactado en los finales del año de 1956). Al mismo tiempo que se imprimía ese Suplemento, dicho discurso entraba a prensas (sin saberlo este Instituto) como parte de un volumen de las Memorias de la Academia Mexicana. Así pues, el estudio de Toussaint sobre Fernández de Andrada y la Epistola Moral, salió realmente a la luz pública en el curso del año de 1957. 2

1 Otra versión dice: "y donde al más astuto nacen canas".

2 Manuel Toussaint: "La Epístola Moral a Fabio", en Memorias de la Academia Mexicana (Discursos Académicos), tomo xv. Editorial Jus, México, 1956. pp. 125-136. [El colofón dice: "Acabóse de imprimir esta obra el día 30 de diciembre de 1956". Como es lógico, el volumen saldría de la imprenta varias semanas después y sería puesto en circulación ya bien avanzado el año de 1957]. 
En su estudio Toussaint se apoya en la hipótesis, que parece cierta y es hasta hoy la mejor fundada, de que el autor de la Epistola Moral lo fue el Capitán Andrés Fernández de Andrada, basándose en el epígrafe de uno de los primeros manuscritos de ese poema, que dice: "Copia de la carta que el capitán Andrés Fernández de Andrada escribió desde Sevilla a D. Alonso Tello de Guzmán, pretendiente en Madrid, que fue corregidor de la ciudad de México." 3

El hallazgo de Toussaint fue encontrar que Fernández de Andrada vivía en la Nueva España poco antes de mediar el siglo xvir. El párrafo que resume su noticia dice así:

“... En efecto, consta que en 1646, el 14 de octubre, el capitán Andrés Fernández de Andrada vecino de la ciudad de México, por sí y por doña Antonia de Velasco, vecina de la provincia de Cuautitlán, estante en su hacienda de labor llamada Santa Inés, su legítima mujer, tiró escritura ante el notario Francisco Olalde en obligación de un mil pesos a favor de Juan González. Dos días antes, es decir, el 12 de octubre, la señora Velasco había dado poder a su marido para extender la escritura y en él se lee que Fernández de Andrada era vecino de Güegüetoca (sic) (Nota al pie: Los documentos citados se encuentran en el protocolo del Notario Francisco Olalde No 294 (1646-1648) Fol, 199). Poco después Fernández de Andrada, Alcalde Mayor por S. M. del partido de Ixmiquilpan da poder a don José de la Mota y Portugal, vecino de México, para todos sus asuntos.

"La interpretación correcta de estos tres documentos es, a mi modo de ver, como sigue: Andrés Fernández de Andrada fue vecino de Huehuetoca hasta el 12 de octubre de 1646 en que pidió poder a su esposa, doña Antonia de Velasco, señora rica, dueña de la hacienda llamada Santa Inés en la jurisdicción de Cuautitlán, para poder extender la escritura que al día siguiente tiró el notario Francisco Olalde, por mil pesos que recibió en calidad de préstamo de Juan González. Esta suma sería para arreglos de su viaje e instalación en Ixmiquilpan de donde había sido nombrado Alcalde Mayor. Antes de emprender la cabalgata a su destino, extendió poder a don José de la Mota y Portugal para que entendiese en todos sus asuntos en la capital del virreinato." 4

3 op. cit., p. 127.

40 p. cit., p. 129. 
En cuanto a la Epistola, por diversas razones está probado que no pudo ser escrita antes de 1631; por otra parte, Tello de Guzmán, a quien está dedicada, fue Corregidor de México de 1613 a 1618. Eso llevó a Toussaint a suponer que el excorregidor regresó inmediatamente depuesto el cargo, a España, y allí volvió a "pretender", y que el poema (que es una escéptica meditación contra la vanidad de los cargos y honores y un elogio de la aurea mediocritas en la tierra natal), tuvo que ser redactado entre los años de 1618 y 1631, y dice: "Yo creo que debemos acercarnos a la fecha más temprana de 1618, cuando el tema inspirador el corregimiento de Tello de Guzmán que terminó ese año, se encontraba en su mayor efervescencia, más en caliente, como decimos en México." s

En sintesis, de los datos y de ciertas frases del poema que le parecen alusivas a un anterior viaje trasatlántico y a cosas de nuestro pais, Toussaint concluye que:

"Podrán ser exactas estas alusiones o rechazadas como fantasías imaginativas; pero me dan pie para formular mi hipótesis, aprovechando los datos históricos que he consignado, acerca del poeta y de su estancia en México que contribuyen, en algo, a esclarecer el problema y a fortificar su atribución a Fernández Andrada.

"El poeta estuvo en Nueva España antes de escribirlo en Sevilla el año de 1618. Probablemente conoció o se relacionó aquí con don Alonso de Guzmán quien regresó a Madrid y siguió su empeño de solicitante en la corte. La estancia en México fue funesta para ambos y de esa desilusión de la vida surge esta carta...

"Pasan los años, Fernández de Andrada aparece de nuevo en México en 1646. Los tiempos han cambiado; ha contraido matrimonio con una señora rica: doña Antonia de Velasco, emparentada acaso con los Velasco virreyes de Nueva España. Ha obtenido la Alcaldía Mayor de Ixmiquilpan. La vida ha cambiado: La Epístola melancólica yace abandonada en manos de los copistas que la modifican a su antojo..."

Cinco años después que Toussaint e ignorando su hallazgo, según 5 op cit., p. 128.

op. cit., p. 132. 
se colige por el absoluto silencio al respecto, el filólogo español don Dámaso Alonso discurrió asimismo y mucho más largamente por esos rumbos de la Epistola; aunque persiguiendo directamente una distinta finalidad encontróse, también, con un Andrés Fernández de Andrada en la burocracia de México.

El trabajo de Dámaso Alonso: El Fabio de la "Epistola Moral": su cara y cruz en Méjico y en España, formando parte de un volumen junto con otro ensayo aparece publicado en Madrid en 1960, aunque parece haber llegado aquí bastante más tarde. ${ }^{7}$ En él, una nota final nos dice que el estudio sobre Fabio fue redactado en 1959 , pero por la nota 1 del cap. 11, p. 114, se ve que Alonso estaba trabajando en el tema ya en 1958, encargando ciertas copias, en microfilm, de documentos de archivos mexicanos por medio de amigos y colegas residentes aquí. ¿Cómo nada supo del discurso de Toussaint lefdo públicamente en 1954 y ya publicado en 1957?

Dámaso Alonso encaminó su investigación hacia el sujeto a quien el poema va dedicado, como antes quedó dicho, ese Fabio que se dice fue don Alonso Tello de Guzmán; es decir, también Alonso parte de la base de que la dedicatoria es veraz, lo cual implica que el autor de los tercetos lo fue Andrés Fernández de Andrada. Dejando aparte, para sólo aludirlos después, varios puntos del asunto en cuestión, vamos a ver primordialmente y casi exclusivamente, el punto en que el estudio de Dámaso Alonso se conecta con el de Manuel Toussaint, sin que, como veremos, lleguen a tocarse.

Por una serie de bien establecidas deducciones, cuyo erudito fundamento no puede reducirse a tres líneas y el lector interesado hará bien de estudiar en el texto que referimos, Dámaso Alonso se inclina, decididamente, a aceptar que Andrés Fernández de Andrada fue el autor de la Epistola Moral y, luego, que ésta fue escrita en Sevilla "entre diciembre de 1610 y los principios de 1611 , pero no más tarde", 8 es decir, cuando Tello de Guzmán pretendía en Madrid, antes de obtener cl corregimiento de México, y no luego de terminado éste, como supuso don Manuel Toussaint.

7 Dámaso Alonso: Dos españoles del siglo de oro. Un poeta madrileñista, latinista y francesista en la mitad del siglo xvi. El Fabio de la "Eptstola Moral": su cara y cruz en Méjico y en España. Biblioteca Románica Hispánica. Editorial Gredos. Madrid, 1960. (El Fabio de la "Epístola Moral"... pp. 103-238.)

8 op. cit., p: 225. 
Respecto al mencionado autor del poema, el señor Alonso encontró, en el Libro 23 de Actas de Cabildo de México, no menos de una docena de menciones de Andrés Fernández de Andrada como Contador de Bienes de Difuntos, en el año de 1619, el siguiente a la terminación del cargo de Corregidor de Tello de Guzmán. ${ }^{\circ}$

En cuanto a este último personaje (cuya vida, o parte de ella, se nos da con riqueza de detalles, con gran interés, y con ameno estilo), tampoco estaba en Sevilla inmediatamente después de dejar su cargo en 1618, porque se quedó en la Nueva España: luego de Corregidor de México, época en que casó aquí con una hija del Mariscal de Castilla, fue Alcalde Mayor de la Puebla, en 1620, y más tarde, en 1622, el virrey Conde de Priego informa que Tello de Guzmán es Alcalde Mayor de las Minas de San Luis y Teniente de Capitán General en ellas... y hasta ahŕ llega la investigación del señor Alonso. ${ }^{10}$

\section{En resumen:}

A) Hubo un Andrés Fernández de Andrada, sevillano, amigo de Francisco de Rioja, buen poeta aunque pocas obras de él se conocen; tuvo, como dice Alonso, cierta "actividad poética" en España hacia 1610-1611. Parece indudable que ese poeta fue el autor del poema dedicado a don Alonso Tello de Guzmán, la llamada Epistola Moral, y que ésta fue escrita antes de 1612, según dice Alonso, y no en 1618 como equivocadamente supuso Toussaint.

B) Un Andrés Fernández de Andrada ocupaba, en México y en 1619, el cargo de Contador de Bienes de Difuntos. (Hallazgo de Dámaso Alonso). Parece probable que fuese este funcionario la misma persona que el sevillano, quien habría venido a México seis años antes cuando su amigo Tello de Guzmán llegó nombrado Corregidor.

C) Un Capitán Andrés Fernández de Andrada vivía en el valle de México, Huehuetoca y Cuautitlán, en 1646, y ese año fue designado Alcalde Mayor de Ixmiquilpan. (Hallazgo de Manuel Toussaint).

¿Era este capitán el mismo Andrés Fernández de Andrada que fue Contador 27 años antes y el mismo que escribla poemas en Sevilla, 35 años atrás? Todo lo poco que sabemos concurre a suponer que así fue: el no figurar entre los poetas españoles Fernández de Andrada des-

O Op. cit., p. 227 y p. 230 nota 6.

10 Op. cit., p. 222. 
pués de 1612 ó 1613 se explicaría porque en esa fecha debió haber salido de España en compañia de Tello de Guzmán, pero ¿por qué no aparece como poeta aquí en México, siendo conocido ya como tal en España y apreciado por poetas de renombre como Rioja (que, además, era tan altivo y parece que de no muchos amigos) que allá en Sevilla le había dedicado una silva titulada "Al verano”? 11 ¿Sucedería, acaso, que Fernández de Andrada, años después de escritos sus magníficos tercetos, cumplió de verdad el deseo que allí parece sólo una proposición poética tantas veces repetida desde Horacio?:
Una mediana vida yo posea, un estilo común y moderado que no lo note nadie que lo vea...

¿Eso, que parece sólo una de tantas expresiones poéticas del beatus ille horaciano, tan repetido por renacentistas y barrocos, lo hizo concreta realidad casando aquí con criolla rica y ocupando, de tarde en tarde, algún cargo de poco brillo y provecho cierto?

De haber sido así, ¿cómo vivía este capitán horaciano y senequista? Tal vez en su casona de Huehuetoca o de Cuautitlán, alternaba el cuidado de su hacienda con el cultivo de los libros, si es que cumplia lo que en sus hermosos, juveniles tercetos, anhelaba:

Un ángulo me basta entre mis lares un libro y un amigo, un sueño breve que no conturben deudas ni pesares.

Finalmente, ¿guardará, algún sitio de nuestro país: México, Ixmiquilpan, San Luis Potosí, el polvo de los restos del autor y del destinatario de aquel poema, uno de los más hermosos y de los más célebres que produjo el siglo de oro español?

Acaso tengamos un día las respuestas, si algún investigador sigue por ese camino que señalan los hallazgos de Manuel Toussaint y de Dámaso Alonso.

Indebido sería terminar estas notas sin apuntar, al menos, la importancia del bien hecho y bien escrito ensayo El Fabio de la "Epistola 11 op. cit., p. 224. 
Moral". Muchos personajes de diversa índole pasan por allí (aparte de aquél a quien principalmente está consagrado) : el Licenciado Ruiz de Alarcón, que sale bien librado de un juicio de residencia; el malhumorado y codicioso Mariscal don Carlos de Luna y Arellano; el Virrey Guadalcázar; los Regidores que suelen no asistir al Cabildo; la visita de un corsario inglés al puerto de Acapulco; las trapisondas y muy turbios manejos de funcionarios, que medran contra la ley por medio de segundas manos, picardías que todos conocen pero que oficialmente se ignoran (me estoy refiriendo al siglo xvir o ¿sospecha el lector que he saltado a la crónica contemporánea?) ; los oficios, las fiestas, "un bullir de vida" en fin como dice el propio autor; todo lo cual enriquece y engalana las cualidades específicas de este ensayo de historia de la literatura. Que el mucho saber no estorba para ver la vida, ni la erudición quita soltura ni agilidad, como lo demuestran esas ricas y gratas páginas que los curiosos y estudiosos de las cosas de Nueva España debemos agradecer. 